K

B

\title{
The right to education as a fundamental right in democracy
}

Maria Magalhaes Silva ${ }^{a^{*}}$,

Dora Resende Alves ${ }^{b}$,

$\mathrm{K}^{\mathrm{K}}$

Suggested Citation:

B

B

B

B

Abstract

K

K 
1. Introduction

K

2. The question of the right to education 
K

3. The Right to Education in the Portuguese Constitution $\mathrm{K}$

KK HK K

4. The Right to Education in the European Union

K

K

K

B

B KK

B

KKK B

K B

K

B

K 
B

5. The Role of Universities and the Right to Education

B 
K

B

B

B

6. Conclusion 
References

B

K

B

${ }_{B}^{B}$

K 